\title{
Risk Factors of Pulmonary Tuberculosis and Countermeasures: A Literature Review
}

\author{
Edza Aria Wikurendra ${ }^{1,2 *}$, Novera Herdiani ${ }^{2}$, Yenni Gustiani Tarigan ${ }^{3}$, Arie Arizandi Kurnianto ${ }^{4}$ \\ ${ }^{1}$ Doctoral School of Management and Organizational Science, Faculty of Economic Science, Magyar Agrár-és Élettudományi \\ Egyetem, Kaposvár, Hungary; ${ }^{2}$ Public Health Study Program, Faculty of Health, Universitas Nahdlatul Ulama, Surabaya, \\ Indonesia; ${ }^{3}$ Public Health Study Program, Faculty of Pharmacy and Health Sciences, Sari Mutiara Indonesia University, Medan, \\ Indonesia; ${ }^{4}$ Doctoral School of Health Sciences, Faculty of Health Sciences, University of Pécs, Pécs, Hungary
}

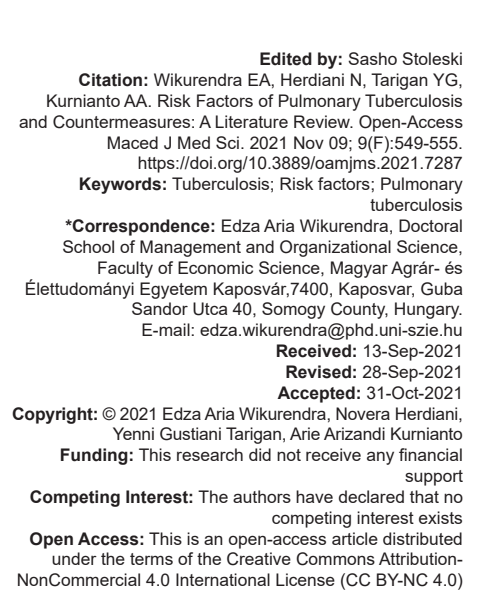

\section{Introduction}

Health development is an effort carried out to increase awareness, willingness, and ability to live a healthy life for everyone to realize the highest public health status. This effort should be made as an investment for the development of socially and economically productive human resources. To achieve an optimal degree of public health, the Disease Eradication Program focuses on preventing disease outbreaks, reducing morbidity and mortality, and reducing the adverse effects of communicable and noncommunicable diseases. In the 2015-2019 strategic plan of the Ministry of Health, infectious diseases such as HIVIAIDS, tuberculosis (TB), malaria, dengue hemorrhagic fever, influenza, and bird flu are the main priorities that must be realized to create a healthy Indonesia [1].

Pulmonary TB is an infectious disease caused by Mycobacterium tuberculosis, which manifests in the lungs. These mycobacteria are transmitted through airborne droplets from a patient with pulmonary TB. TB control efforts have been made through various health programs at the Community Health Center level. One of them is developing a TB control strategy known as the strategy Directly Observed Treatment Shortcourse (DOTS). DOTS has been shown to suppress transmission and prevent development (Multi Drugs Resistance) TB. The more indication found for TB patients, antiretroviral therapy enhances longevity, is quite well controlled, and thus can be tailored to control associated symptoms with empirical regimen of pulmonary TB. Moreover, synthetic glucocorticoid is beneficial both within the prevention and treatment of counterintuitive for the case that pulomoary TB with severe immune inflammatory symptom [2]. However, the results of its implementation in Indonesia are still not as expected.

Until now, pulmonary TB is still a significant health problem in the world and Indonesia. The World Health Organization reported the prevalence rate of pulmonary TB cases in Indonesia in 2016, approximately 130100,000 population with 539,000 
new cases and around 101,000 deaths/year. Acid-fast bacilli (AFB) pulmonary TB $(+)$ incidence rate is about $110 / 100,000$ population [3]. This disease is the third cause of death after heart disease and respiratory tract disease in Indonesia [4]. In the Annual Report on Global TB TB Control (2003), the WHO states Indonesia is one of 22 countries categorized as high-burdened countries for pulmonary TB. In 2004 an estimated 2 million people died worldwide due to pulmonary TB from 9 million cases. Due to its sizeable population, Indonesia ranks third globally in pulmonary TB after India and China [5]. Each year the estimated number of new cases ranges from 500 to 600 people among 100,000 inhabitants [4].

Nevertheless, in particular, the treatment program also needs additional measures to improve literacy in pulmonary TB treatment. Another factor that has to be considered is the capacity of human resources to manage TB. In addition, the enhanced integration technologies in terms of interconnection are often very important to track treatment in such a form that it would be comprehensive [6].

Approximately $75 \%$ of patients with pulmonary TB are in the economically productive age group (1550 years). It is estimated that an adult with pulmonary TB will lose an average of 3-4 months of working time. The results in an annual loss of household income of around $20-30 \%$. If a person dies from pulmonary TB, this person will lose your income for about 15 years. Apart from being economically detrimental, pulmonary TB also has a negative social impact, especially being ostracized by society [4]. Throughout a study performed in two groups of children, including those detected by diagnostic procedures and clinically diagnosed as multidrug-resistant TB, it was observed that several diseases were transmitted simultaneously in the group of children who clinically diagnosed [7].

Moreover, the number prevalence pulmonary TB among healthcare workers in South Africa had been also a serious indication for the severity transmission of pulmonary TB. The wide spread of transmission also influenced by literacy, self-awareness of personal hygiene, and the strengthen support from stakeholders [8]. Furthermore, with the complexity of risk factors may associated with the increasing number of pulmonary TB prevalence, it is also needed to consider the heredity factors that may play a big role in the outcomes of treatment period [9]. The genomic structure is essential to determine the rational and effective treatment and regiments for patients with pulmonary TB in responding to obtain the outcomes [10].

In addition, being one of the most infectious ailments in public health, one of the leading crossfunctional to an escalation of incidents for pulmonary TB is a disparity in diagnosis, which deteriorates patients' health condition and severity [11]. The following characteristics were various treatment disruptions were employment, information level, initial attending to healthcare service, and receiving therapy from a mystical or conventional therapist without first visiting a medical facility [12]. Therefore, this study aimed to identify the influencing factors and efforts to overcome pulmonary TB disease.

\section{Research Method}

This research was a literature review that used a meta-synthetic approach. This literature review was conducted in articles published in Google Scholar. The search terms or keywords used are "risk factor of TB" or "measurement TB." Search limits included: English and Indonesian language, but there were no limits for the year of publication or study. Finally, 38 articles were found and then there was the extraction of articles to answer this study's purpose.

\section{Results and Discussion}

\section{Risk factors associated with pulmonary $T B$ incidence}

TB is a pulmonary infectious disease caused by bacteria. Factors that influence TB infection incidence include age, income level (socioeconomic), housing conditions, the behavior of opening windows every morning and smoking, and a history of contact with TB patients. Age plays a role in the incidence of TB. The risk of TB infection can be said as a normal curve is reversed. Ages $0-12$ years have a high risk of TB infection and will then decline at the age of more than 2 years to adulthood because, at that age, a person has good resistance to TB. Furthermore, the risk of infection will again increase when a person approaches old age [13].

Income levels (socioeconomic) affect the incidence of TB. Family heads who have an income below the Regional Minimum Wage will consume foods with nutritional levels that are not suitable for each family member's needs. A lack of nutritional status in a person will facilitate disease infections, one of which is pulmonary TB [13]. Nutritional status and infectious diseases are closely related partners. Patients with infection often experience anorexia, use excessive time, decrease in nutrition, or malnutrition will have low immunity and are very sensitive to disease transmission. In a state of poor nutrition, the immune response will reduce so that the ability to defend itself against infection decreases [14]. Furthermore, unfavorable socioeconomic conditions can cause sufferers not to have the ability to build a healthy or eligible house. Lack of knowledge to obtain health information, the inadequate reach of health services 
and lack of nutritional fulfillment can result in a low immune system making it easy to become infected [15]. Knowledge and education contribute to a person's health behavior. The low education level will affect how much experience a person, especially in healthy behavior [16]. Policymakers and systems integration have to speed up social and economic changes through community health to offer more resources for patients to mitigate quality of life deficiency of patient with pulmonary TB [17].

A systematic review of the predictive variables with fatalities among patients diagnosed pulmonary $\mathrm{Tb}$ indicates there is a correlation with triggers that may exacerbate the condition of patients with cases of pulmonary TB who died even after hospitalization. Degenerative disease conditions and cases of patients that have cancer complications often disrupt the treatment of patients with TB which might have drugs with immunostimulatory effects that interrupt the outcomes of the TB regimen [18]. Patients rarely miss the treatment even during recovery [19].

Home conditions are also a risk factor for pulmonary TB transmission. Roofs, walls, and floors can be breeding grounds for germs. Floors and walls that are difficult to clean will cause dust buildup, making them a suitable medium for multiplying germs. The behavior of a person accustomed to opening the window every morning and smoking also affects pulmonary TB incidence. The activity of opening windows every morning is one way to prevent pulmonary TB because sunlight can enter the house or room to kill the bacteria that cause pulmonary TB [13]. Less light causes the TB germs to survive in a cool, humid, and dark place without sunlight for years.

Moreover, the less ventilation area causes an increase in room humidity due to the evaporation of fluids from the skin. High humidity in the room will be a suitable medium for the growth and breeding of pathogenic bacteria, including TB germs [15], [16]. In poor ventilation conditions, the air is trapped in the room, and the room becomes stuffy and humid. Humidity in the house facilitates the breeding of the bacteria M. tuberculosis, and the state of air ventilation in small spaces is closely related to the incidence of pulmonary TB ventilation $<15 \%$ of the floor area at risk of pulmonary TB 16.9>. Bedroom ventilation plays a significant role in air circulation, especially removing $\mathrm{CO}_{2}$, including contaminated materials such as bacteria, so that a room's ventilation does not meet minimum standards. The transmission of pulmonary TB bacteria will mostly strike relatively healthy social encounters when they are in a damp, dirty, and poor lighting building [20].

In regards, the condition worsens with space which will become hot, and the air stagnates in it, eventually endangering the wearer [14]. Furthermore, ventilation is essential so that sunlight can enter the house [16]. Some clinicians found the patients frequently suffering with blocked breathing, whereby patients typically involve chest pressure, coughing, and breathlessness [21]. Besides, factors in house conditions that do not meet health requirements such as non-permanent walls, high occupancy density, no garbage disposal, dirt-floored houses, and consuming water that does not meet the criteria are also factors that can increase the incidence of TB infection in the household [22].

Meanwhile, smoking can worsen the symptoms of TB [13], [22]. Likewise, passive smokers who inhale cigarette smoke will make passive smokers more easily infected with pulmonary TB. A history of contact with a patient with pulmonary TB can accelerate pulmonary TB cases because an average patient can transmit the bacteria to 2-3 people in the same room. The risk of transmission for households with more than one patient with pulmonary TB is 4 times that of families with only one patient with pulmonary TB [13]. When there is a history of the transmission of family members who suffer from pulmonary TB, it will transmit 79.781 times more than families without pulmonary TB. Some related factors may be associated with pulmonary TB found such as age, comorbid conditions, immunity condition, dietary condition, substance abuse, medication management, and medication sensitivity [19].

A history of contact with other family members who are suffering from pulmonary $T B$ is critical because $M$. tuberculosis is very small, aerobic, and can survive in dry sputum or other excreta, and is highly contagious. Through inhalation excretion either through breath, coughing, sneezing, or speaking (droplet infection). When one family member is suffering from active pulmonary TB, all other family members will be susceptible to the disease, including close family members. Hereditary features influence the uptake and processing of drugs and the human susceptibility to toxicity [19]. A history of contact with family members in the same household and have had contact for $\geq 3$ months at risk for infection with pulmonary TB, especially excessive contact through smell, hug, and speaking. The results showed that $63.8 \%$ of pulmonary TB patients came from household contact with family or parents who suffered from pulmonary TB [14].

In addition, the profound factor may associated with the steady flow of pulmonary TB prevalence's was about occupation. It has been reported it has been followed by the worsen with the inadequate of literacy of TB or pulmonary related disease treatment. For instance, the decreased self-rated well-being of mineworkers was evaluated by project type [23]. Based on the data from International Labor Organization (ILO) revealed the mining industry accounted for more than a quarter percent of cases of occupational diseases and accidents recorded between 2003 and 2007. International humanitarian organizations are now posing a growing number of claims of health risks for employees as a result of inadequate working conditions and abuses of power [24]. 


\section{Counter measurement of pulmonary TB}

There are various countermeasures undertaken to overcome pulmonary TB, one of which uses a tissue model. Even though the initial model applied in animal studies, it has been developed recently an examination concern about the ability and shortcomings of various scientific techniques used in TB studies, with an emphasis on animal and human-based cell culture models. The most recent developments in designing as a novel method for studying M. tuberculosis infection [25]. This model involves many stakeholders whose duty is to provide knowledge and record the number of sufferers. The TB Eradication Operational Network that was developed consisted of Tjekyan [26]:

a. Establish a formal sub-district level organization, namely, the "Pulmonary TB Eradication Network" created by the District Government through inauguration with a District Head Decree.

b. TB health promotion is the activity of detection and referral of suspected pulmonary TB by neighbor-level TB cadres. Suspect referrals are addressed to Urban Village Private doctors and the TB Prevention and Control Section at Community Health Centers by completing a particular referral form.

c. Recruitment of village private practicing doctors is carried out because they are proficient in managing TB cases, DOTS strategy, fixeddose regimen, recording system, and reporting as a pulmonary TB health service unit in each village.

d. Diagnosis of TB is carried out by microscopic examination of sputum with a sensitivity of $78 \%$ and a specificity of $97 \%$. The method used is the Sodium Hypochlorite centrifugation method in TB Prevention and Control. The TB Prevention and Control Laboratory were upgraded as a microscopic referral center limited specifically for districts.

e. Anti-TB drugs with Fixed-Dose supervised by two Drug Ingestion Supervisors consisting of their closest family members and two-direct observer TB cadres.

f. Use of Fixed-Dose Anti-TB Drugs whose availability is guaranteed by the sub-district TB Control, TB Prevention and Control at community health centers and health offices.

g. Recording and reporting by Private Practitioners using TB 01 and TB 06 forms facilitated by the District TB Control Network, which is then reported to TB Prevention and Control at the community health center.

h. The recruitment of new TB cadres is obtained from the tissue of patients who have recovered. The stages of action to control TB include discovery, treatment, and surveillance [27]: a. The stages of discovery

The discovery of a suspected TB patient in the form of a cough with phlegm for more than 2 weeks whose cause could not be explained. While in children, there is a history of contact with a patient diagnosed with TB. For this finding's sub-indicators, the experts participating in the discussion recommended a standard TB diagnosis method formulation as a reference for all implementers in the field. Five items were successfully explored and concluded at the TB case detection stage:

1) Development of TB suspects criteria determination. Indicator: Suspect Selection Number.

2) Sputum inspection/sampling modification at Time-Morning-Time (SPS). Indicators: The proportion of AFB (+) among suspects and proportion of AFB (+) among all TB patients.

3) Thorax Photo Optimization to support SPS. Indicators: suspect screening figures and Case Detection Rate (CDR).

4) Diagnosis of TB in children based on the scoring system. Indicator: The proportion of child TB among all TB sufferers.

5) Identification and evaluation of intensive contacts. Indicator: CDR and case notification rate (Handling Indicator).

b. The stages of treatment

Five items were successfully explored and concluded at the TB case treatment stage:

1) Measurement of medication adherence. Indicators: conversion rate, cure rate, and treatment success rate.

2) Drug supply management. Indicator: Available/ not.

3) Drug response assessment. Sputum examination of two specimens at the end of the intensive phase. $1 \times$ sputum examination at the end of the $5^{\text {th }}$ month. Examination of sputum $1 \times$ at the end of therapy. Indicators: conversion rate, cure rate, Success Rate/SR.

4) HIV Counseling and Testing for Patients with TB. Indicator: Done/not.

5) Availability of second-line Anti-TB Drugs. Indicator: available/not.

c. The stages of surveillance

Four items were successfully explored and concluded at the TB case surveillance stage:

1) Sputum culture development for AFB (+). Indicator: Error Rate.

2) Culture development for patients with AFB (-) TB. Indicator: Error Rate.

3) Completeness of medical records. Indicator: complete/not.

4) Reporting: New cases, repeated cases, and treatment results. Indicator: done/not.

Steps to control TB in Public Health Centers, according to other research [28]: 
a. Passive case finding is patients who visit for treatment with complaints, like symptoms or signs of TB disease clinically and actively from the families of patients at risk of contracting TB.

b. Laboratory tests to confirm TB + or not (suspect).

c. Patients who are positive for TB will be subjected to a home visit examination by a health worker to determine whether family members have had contact with the patient (contact tracing).

d. Furthermore, Community Health Nursing ( $\mathrm{CHN})$ format is recorded specifically to document TB sufferers. The forms that need to be filled are Form TB 01 and Form TB 02 for patients and Form TB 03 for recording in the register book.

e. TB cases are reported to the Health Office every month for new patients via SMS and every 3 months as a register or cohort report, which also serves as monitoring and evaluation.

In addition to several attempts to overcome the TB infection, increased knowledge, positive attitudes, and treatment compliance for pulmonary TB patients must also be realized through counseling. That is because the information needs of patients undergoing pulmonary TB treatment are very high [29]. Patients who undergo pulmonary TB treatment need information or health counseling about TB treatment and treatment [30]. Providing counseling with a group counseling model is more effective than the individual counseling model. Providing group counseling is more effective in terms of time, financial resources, and resources [31]. The kind of counseling can be cognitive intervention and clinical education for pulmonary TB patients on a daily basis [32].

In addition to providing counseling and health education about pulmonary TB and teaching necessary care skills to meet basic human needs, nurses as health workers need to give support or support to families. Focus on providing comprehensive counseling on the treatment of pulmonary TB that consequently tailored and detailed advice would deliver positive results [33]. There is indeed a step in order associated person on the treatment of pulmonary TB in the local community. Member of the family of them is through diagnostic support testing to confirm that TB patients are recurrent infections of TB before further treatment. This will promote the rationality of adequate treatment for the severity of pulmonary TB [34]. That is because the process of healing or recovering a patient needs human attention as a whole (holism), namely, bio, psycho, socio-cultural, and spiritual [35].

The immediate family's role, such as the wife and children of patients with pulmonary $\mathrm{TB}$, is very significant in pulmonary TB sufferers' healing process at home. Wife and children as caregivers carry out family functions, as the part of family healthcare. There are five family functions: The affective function, socialization, social placement function, the health-care function, the reproductive function, and the economic function [36]. It has always been recommended that medical professionals, patients and family members medication management be strengthened and that budgetary funding for enhancing commitment be increased [37]. Therefore, in realizing adequate health service facilities to control pulmonary $\mathrm{TB}$, it is necessary to provide quality health services such as health counseling rooms [38].

\section{Conclusion}

Pulmonary TB is still a problem in developing countries like Indonesia and even in developed countries. This problem reappeared in the presence of HIVIAIDS. Factors that influence TB infection incidence include age, income level (socioeconomic), housing conditions, the behavior of opening windows every morning and smoking, and a history of contact with TB patients. Various attempts have been made to treat or reduce pulmonary TB infection incidence using a tissue model. This model involves many stakeholders whose duty is to provide knowledge and record the number of sufferers. The stages of action to control TB include discovery, treatment, and surveillance. Facts in the field show that several factors can affect the success of implementing pulmonary TB control. Therefore, it is necessary to participate in all society components and involve other agencies beyond the health agency so that the reduction in the incidence of pulmonary TB can be appropriately realized.

\section{References}

1. Ministry of Health of the Republic of Indonesia. Ministry of Health Strategic Plan 2015-2019. Jakarta: Ministry of Health of the Republic of Indonesia; 2015. Available from: http://ppid.kemkes.go.id/uploads/ img_5cd07f7e6d039.pdf. [Last accessed on 2021 May 16].

2. Meintjes G, Brust JC, Nuttall J, Maartens G. Management of active tuberculosis in adults with HIV. Lancet HIV. 2019;6(7):e463-74. http://doi.org/10.1016/S2352-3018(19)30154-7

PMid:31272663

3. World Health Organization. Global Tuberculosis Report. Paris World Health Organization; 2015. Available from: https:/lapps. who.int/iris/bitstream/handle/10665/191102/9789241565059_eng. pdf?sequence=1\&isAllowed=y. [Last accessed on 2021 May 16].

4. Ministry of Health of the Republic of Indonesia. National Guidelines for Tuberculosis Control. Jakarta: Ministry of Health of the Republic of Indonesia; 2014. Available from: https://www.dropbox.com/ s/9ylzsb31c8sw963/pedoman-tbnasional2014.pdf?dl=0\#pedomantbnasional2014.pdf. [Last accessed on 2021 May 16].

5. World Health Organization. WHO Report 2003: Global 
Tuberculosis Control-Surveillance, Planning, and Financing. Geneva: World Health Organization; 2003. Available from: https:// apps.who.int/iris/bitstream/handle/10665/42889/9241562641. pdf?. [Last accessed on 2021 May 16].

6. Alipanah N, Jarlsberg L, Miller C, Linh NN, Falzon D, Jaramillo E, et al. Adherence interventions and outcomes of tuberculosis treatment: A systematic review and meta-analysis of trials and observational studies. PLoS Med. 2018;15(7):e1002595. http:// doi.org/10.1371/journal.pmed.1002595

PMid:29969463

7. Harausz EP, Garcia-Prats AJ, Law S, Schaaf HS, Kredo T, Seddon JA, et al. Treatment and outcomes in children with multidrug-resistant tuberculosis: Asystematic review and individual patient data meta-analysis. PLoS Med. 2018;15(7):e1002591. http://doi.org/10.1371/journal.pmed.1002591

PMid:29995958

8. Engelbrecht M, van Rensburg AJ, Kigozi G, van Rensburg HD. Factors associated with good TB infection control practices among primary healthcare workers in the Free State Province, South Africa. BMC Infect Dis. 2016;16(1):633. http://doi. org/10.1186/s12879-016-1984-2

PMid:27814757

9. Ryan H, Yoo J, Darsini P, Akolo C, Adetifa I, Shepperd S, et al. Community-based supplementary feeding for food insecure, vulnerable and malnourished populations an overview of systematic reviews. Cochrane Database Syst Rev. 2018;15(1):e1002595. PMid:30480324

10. Hersh CP. Pharmacogenetics of chronic obstructive pulmonary disease: Challenges and opportunities. Pharmacogenomics. 2010;11(2):237-47. http://doi.org/10.2217/pgs.09.176 PMid:20136362

11. World Health Organization. Situation Report-81 April 10, 2020. Geneva: World Health Organization; 2020.

12. Alema HB, Hailemariam SA, Misgina KH, Weldu MG Gebregergis YS, Mekonen GK, et al. Health care seeking delay among pulmonary tuberculosis patients in North West zone of Tigrai region, North Ethiopia. BMC Infect Dis. 2019;19(1):309. http://doi.org/10.1186/s12879-019-3893-7 PMid:30953459

13. Fitriani E. Risk factors associated with pulmonary tuberculosis. Unnes J Public Health. 2013;2(1):1-7.

14. Sudiantara K, Putu N, Wahyuni I. Factors affecting the increase in pulmonary tuberculosis cases. J Gema Keperawatan. 2012;7(2):195-200

15. Kurniasari RA, Cahyo K. Risk factors for pulmonary tuberculosis in Baturetno District, Wonogiri Regency. Media Kesehat Masy Indones. 2012;11(2):198-204.

16. Firdiansyah $\mathrm{WN}$. The influence of home sanitation and socioeconomic factors on the incidence of pulmonary tuberculosis in Genteng District, Surabaya City. Swara Bhumi e-J Pendidik Geogr FIS Unesa. 2014;3(3):210-8.

17. Aggarwal AN. Quality of life with tuberculosis. J Clin Tuberc other Mycobact Dis. 2019;17:100121. http://doi.org/10.1016/j. jctube.2019.100121

PMid:31788563

18. de Almeida CP, Ziegelmann PK, Couban R, Wang L, Busse JW, Silva DR. Predictors of in-hospital mortality among patients with pulmonary tuberculosis: A systematic review and meta-analysis. Sci Rep. 2018;8(1):7230.

19. Rabahi MF, da Silva Júnior JL, Ferreira AC, TannusSilva DG, Conde MB. Tuberculosis treatment. J Bras Pneumol. 2017;43(6):472-86. http://doi.org/10.1590/ S1806-37562016000000388

PMid:29340497
20. Carvalho AC, Cardoso CA, Martire TM, Migliori GB, Sant'Anna CC. Epidemiological aspects, clinical manifestations, and prevention of pediatric tuberculosis from the perspective of the End TB Strategy. J Bras Pneumol. 2018;44(2):134-44.

21. Ravimohan S, Kornfeld H, Weissman D, Bisson GP. Tuberculosis and lung damage: from epidemiology to pathophysiology. Eur Respir Rev. 2018;27(147):170077. http:// doi.org/10.1183/16000617.0077-2017 PMid:29491034

22. Girsang M, Tobing K, Rafrizal. Factors causing tuberculosis incidence and its relationship with the living environment in Central Java Province. Bul Penelit Sist Kesehat. 2011;39(1):34-41.

23. Ohnishi M, Tembo B, Nakao R, Matsuura E, Fujita W. Factors associated with self-rated health among mineworkers in Zambia: A cross-sectional study. Trop Med Health. 2021;49(1):11. PMid:33522970

24. Wells M. Labor Abuses in Zambia's Chinese State-owned Copper Mines HRW. Human Rights Watch; 2011. p. 1-130.

25. Fonseca KL, Rodrigues PN, Olsson IA, Saraiva M. Experimental study of tuberculosis: From animal models to complex cell systems and organoids. PLoS Pathog. 2017;13(8):e1006421. http://doi.org/10.1371/journal.ppat.1006421 PMid:28817682

26. Tjekyan RM. Results of one year of intervention of pulmonary tuberculosis control network, Ilir Barat II District, Palembang City. J Kedokt Brawijaya. 2008;24(2):1-7.

27. Laksono AD, Astuti WD, Waty E, Atto'illah. Review the tuberculosis minimum health service standard associated to indicators of millenium development goals. Bul Heal Syst Res. 2012;15(3):259-70.

28. Izza N, Roosihermatie B. Increase of tuberkulosis cases at Pacarkeling Health Center, Surabaya, year 2009-2011. Bul Penelit Sist Kesehat. 2013;16(1):29-37

29. Corones K, Coyer FM, Theobald KA. Exploring the information needs of patients who have undergone $\mathrm{PCl}$. $\mathrm{Br} \mathrm{J}$ Card Nurs. 2009;4(3):123-30.

30. Izzati S, Basyar M, Nazar J. Risk factors associated with the incidence of pulmonary tuberculosis in the work area of the Andalas Public Health Center in 2013. J Kesehat Andalas. 2015;4(1):262-8.

31. Parellangi A. Effects of counseling on knowledge, attitudes, and compliance with tuberculosis treatment for patients. Husada Mahakam J Kesehat. 2013;3(6):281-7.

32. Tola HH, Shojaeizadeh D, Tol A, Garmaroudi G, Yekaninejad MS Kebede A, et al. Psychological and educational intervention to improve tuberculosis treatment adherence in ethiopia based on health belief model: A cluster randomized control trial. PLoS One. 2016;11(5):e0155147. http://doi.org/10.1371/journal. pone.0155147 PMid:27167378

33. M'imunya JM, Kredo T, Volmink J. Patient education and counselling for promoting adherence to treatment for tuberculosis. Cochrane database Syst Rev. 2012;2012(5):CD006591. http:// doi.org/10.1002/14651858.CD006591.pub2 PMid:22592714

34. Kim HW, Kim JS. Treatment of Latent Tuberculosis Infection and its Clinical Efficacy. Tuberc Respir Dis (Seoul). 2018;81(1):6-12. http://doi.org/10.4046/trd.2017.0052 PMid:29332319

35. Mitchell-Macaulay D. Exploring Spirituality, Religion and Traditional Healing as Protective Factors in Transcultural Mental Healthcare. Griffith University; 2017. Available from: http://hdl. handle.net/10072/382685. [Last accessed on 2021 May 16]

36. Cummings EM, Keller PS, Davies PT. Towards a family 
process model of maternal and paternal depressive symptoms: Exploring multiple relations with child and family functioning. J Child Psychol Psychiatry. 2005;4(5):479-89. http://doi. org/10.1111/j.1469-7610.2004.00368.x

PMid: 15845128

37. Chen X, Du L, Wu R, Xu J, Ji H, Zhang Y, et al. The effects of family, society and national policy support on treatment adherence among newly diagnosed tuberculosis patients:
A cross-sectional study. BMC Infect Dis. 2020;20(1):623. http:// doi.org/10.1186/s12879-020-05354-3

PMid:32831050

38. Wulansari S, Rukmini R. The availability and properness of the health care facilities for waste handling based on Indonesian topography and geography. Bul Penelit Sist Kesehat. 2016;19(1):33-9. 